\title{
Can Oral Dextrose Gel Reduce the Need for Dextrose Infusion for Neonatal Hypoglycaemia?
}

\author{
Bithi Roy ${ }^{1,2,3 *}$, Justine Caparaz ${ }^{1}$, Tracy Hynes ${ }^{1}$, Dharmesh Shah ${ }^{1,2,4}$ and Tushar Bhuta ${ }^{1,2,5}$ \\ ${ }^{1}$ The Mater Hospital, Sydney, Australia \\ ${ }^{2}$ Discipline of Child and Adolescent Health, Faculty of Medicine and Health, The University of Sydney, Australia \\ ${ }^{3}$ School of Medicine, The University of Notre Dame Darlinghurst, Australia \\ ${ }^{4}$ Westmead Hospital, Westmead, Sydney, Australia \\ ${ }^{5}$ Royal North Shore Hospital, St Leonard's, Sydney, Australia \\ *Corresponding Author: Bithi Roy, The Mater Hospital, Sydney, Australia.
}

Received: August 26, 2019; Published: September 20, 2019

DOI: $10.31080 /$ ASPE.2019.02.0150

\begin{abstract}
Background: Neonatal hypoglycaemia is a leading problem with risk to brain injury if not treated promptly. Standard management of neonatal hypoglycaemia includes enteral feeding and or intravenous dextrose infusion. Oral dextrose gel is now considered as first line treatment for $\geq 35$ week's gestation.

Aim: To ascertain if oral dextrose gel can reduce the prevalence and the duration of intravenous dextrose infusion and length of stay of babies in the neonatal unit.

Method: An observational study from September 2015 to August 2017 was conducted for babies with neonatal hypoglycaemia from 35 - 40 weeks' gestation in the Special Care Nursery at The Mater Hospital Sydney. The study subjects belonged to one of the two groups; Dextrose gel $(\mathrm{n}=59)$ or Non-dextrose gel $(\mathrm{n}=104)$. Data was analysed based on blood Glucose levels $(\mathrm{BGL})(<1.0 \mathrm{mmol} / \mathrm{L}$, $1.0-1.5 \mathrm{mmol} / \mathrm{L}$ and $1.6-2.6 \mathrm{mmol} / \mathrm{L})$.

Results: Incidence of intravenous dextrose infusion was $19 \%$ and $45 \%$ ( $\mathrm{p}=0.05$ ) for BGL $1.0-1.5 \mathrm{mmol} / \mathrm{L}$ and $6 \%$ and $11 \%$ for BGL $1.5-2.6 \mathrm{mmol} / \mathrm{L}$ for Dextrose gel and Non-dextrose gel groups respectively. Average duration of intravenous dextrose infusion ( $\mathrm{p}=$ 0.02 ) and length of stay in the neonatal unit was less for Dextrose gel group compared to Non-dextrose gel group.

Conclusions: Oral dextrose gel was effective in reducing the incidence of intravenous intervention for BGL 1.0 - $1.5 \mathrm{mmol} / \mathrm{L} \mathrm{for} \geq 35$ week's gestation. It was also effective in reducing the duration of intravenous dextrose infusion for asymptomatic neonatal hypoglycaemia. The findings are important when prompt intravenous cannulation for neonatal hypoglycaemia is not feasible.

Keywords: Oral Dextrose; Neonatal Hypoglycaemia
\end{abstract}

\section{Abbreviations}

BGL: Blood Glucose Level

What is already known on this topic

Oral dextrose gel along with enteral feed is an effective first-line treatment for hypoglycaemia in late preterm and term babies in the first 48 hours of age. Dextrose gel is non-invasive, inexpensive and has no known side effect.

What this paper adds

Oral dextrose gel may reduce the need for intravenous dextrose infusion for asymptomatic neonatal hypoglycaemia with BGL 1.0 $1.5 \mathrm{mmol} / \mathrm{L}$ for $\geq 35$ weeks' gestation. This is important in case of limited access to immediate intravenous cannulation.

It may also reduce the duration of intravenous dextrose infusion for asymptomatic neonatal hypoglycaemia.

\section{Introduction}

Neonatal hypoglycaemia is a common problem even in healthy newborn babies [1]. Glucose is the primary source of energy for brain. Fetus derives glucose from the mother via the placenta and after birth, from enteral feeding. Risk factors of hypoglycaemia such as maternal diabetes, antenatal steroids, fetal distress, small or large for gestational age, low birth weight, prematurity, sepsis, polycythaemia, respiratory distress, temperature instability and feed intolerance may interfere with the physiological transitioning of glucose from in-utero to ex-utero period and cause neonatal hypoglycaemia [2-6].

Neonatal hypoglycaemia is defined as blood glucose level (BGL) less than $2.6 \mathrm{mmol} / \mathrm{L}$ [7]. It warrants prompt and appropriate treatment as there is potential risk of seizures, brain damage, neurodevelopmental delay, visual impairment and learning and behav- 
ioural issues [8-12]. Treatment is based on the severity of hypoglycaemia and includes ramifications like admission to neonatal unit, mother-infant separation, hindrance to establishing breast feeding and prolonged hospital stay [13]. The standard treatment options are breast or formula feeding which is mostly done in postnatal wards, unless there is requirement of intra gastric feed or fortified milk formula. The other interventions like intravenous dextrose infusion, glucocorticoids or glucagon administration requires admission to a neonatal unit. Current studies and practices indicate oral dextrose gel is used with increasing frequency as first line treatment for neonatal hypoglycaemia along with enteral feeding [14].

This observational study compared management of neonatal hypoglycaemia before and after introduction of dextrose gel in the Special Care Nursery at The Mater Hospital Sydney. The aim of the study was to ascertain, if use of dextrose gel reduced the need and or the duration of intravenous dextrose infusion and decreased the length of stay of babies in the Special Care Nursery.

\section{Method}

Oral dextrose gel was introduced for treatment of neonatal hypoglycaemia in the Special Care Nursery at The Mater Hospital Sydney in September 2016 [15]. The Mater Hospital is a multi-speciality private hospital with maternity division and a Special Care Nursery. The admissions to the Special Care Nursery are mostly inborn babies from $\geq 32$ weeks' gestation and $\geq 1500$ gm birth weight. About $15-20 \%$ of the babies admitted with or without associated conditions like prematurity, low birth weight, respiratory distress or sepsis have neonatal hypoglycaemia.

As per the revised neonatal hypoglycaemia management policy of the unit, the first line treatment was oral dextrose gel $40 \% \mathrm{w} / \mathrm{v}$ $2.5 \mathrm{ml}$ prefilled syringe by Biomed with a standard dose of $200 \mathrm{mg} /$ $\mathrm{kg} /$ dose, administered by rubbing the dextrose gel with clean gloved finger in the buccal mucosa and enteral feed and or intravenous dextrose infusion [16]. The policy favoured intravenous dextrose infusion for babies with existing intravenous access. Maximum of three doses of dextrose gel was recommended. Mandatory in-service training was provided to the neonatal nurses regarding the revised hypoglycaemia treatment policy and administering of dextrose gel prior to its introduction.

This observational study included two groups from two different epochs, before and after introduction of oral dextrose gel. The groups were called Non-dextrose gel group $(n=106)$ from September 2015 - August 2016 and Dextrose gel group ( $n=59$ ) from September 2016 - August 2017 respectively.

The inclusion criteria for both the groups were inborn infants admitted to the Special Care Nursery from $\geq 35$ weeks' gestation who had neonatal hypoglycaemia with or without other illnesses in the first 24 hours of life as per the definition of American Academy of Paediatrics [7,17]. Infants with congenital malformations were not included.

The data collection was for gestational age, birth weight, common risk factors for neonatal hypoglycaemia, blood glucose levels, types of hypoglycaemia treatments, duration of intravenous dextrose infusion and length of stay of the babies in Special Care Nursery for both the groups.

The study had the ethics clearance from St Vincent's Health Network Sydney (SVH File number: 17/244).

\section{Statistical analysis}

Continuous data were summarized as mean with standard deviation and categorical data by proportions using the independent sample $t$ test. A two-sample t-test was used to compare continuous scales and transformation was conducted for skewed distribution; the $\chi^{2}$ test or Fisher's exact test as appropriate was used for the comparison of categorical data between two groups. All tests were conducted at a two-sided alpha level of 0.05. Analysis was performed with SAS version 9.4.

\section{Results}

The patient characteristics of Dextrose gel and Non-dextrose gel groups are shown in table 1 . The groups were analysed in two ways; an overall analysis (Table 2) and analysis based on blood glucose level (BGL) (Table 3).

\begin{tabular}{|l|c|c|c|}
\hline & $\begin{array}{c}\text { Dextrose gel } \\
\text { group }\end{array}$ & $\begin{array}{c}\text { Non-dextrose } \\
\text { gel group }\end{array}$ & $\begin{array}{c}\boldsymbol{p} \\
\text { value }\end{array}$ \\
\hline $\begin{array}{l}\text { Period of Study: } \\
\text { years }\end{array}$ & $\begin{array}{c}\text { September } \\
2016 \text { - August } \\
2017\end{array}$ & $\begin{array}{c}\text { September } \\
2015 \text { - August } \\
2016\end{array}$ & \\
\hline Total n & 59 & 104 & \\
\hline $\begin{array}{l}\text { GA: mean (range) } \\
\text { weeks }\end{array}$ & $37(35-40)$ & $37(35-41)$ & 0.90 \\
\hline BW: mean (range) gm & 2991 & 2837 & 0.08 \\
\hline M:F & $35: 24$ & $59: 45$ & \\
\hline Preterm infants \% (n) & $42 \%(25)$ & $39 \%(41)$ & 0.71 \\
\hline SGA \% (n) & $12 \%(7)$ & $13 \%(14)$ & 0.77 \\
\hline LGA \% (n) & $8 \%(5)$ & $6 \%(6)$ & 0.51 \\
\hline GDM overall & $34 \%(20)$ & $23 \%(24)$ & 0.13 \\
\hline GDM on diet \% (n) & $17 \%(10)$ & $18 \%(19)$ & 0.83 \\
\hline GDM on insulin \% (n) & $17 \%(10)$ & $5 \%(5)$ & 0.01 \\
\hline Hypothermia \% (n) & $36 \%(21)$ & $22 \%(23)$ & 0.06 \\
\hline
\end{tabular}

Table 1: Patient Characteristics.

†n: Number of Study Subjects; GA: Gestational Age; BW: Birth Weight; M: Male; F: Female; SGA: Small for Gestational Age (birth weight below $10^{\text {th }}$ percentile on Fenton's growth chart); LGA:

Large for Gestational Age (birth weight above $90^{\text {th }}$ percentile on Fenton's growth chart); GDM: Gestational Diabetes Mellitus. 


\begin{tabular}{|l|c|c|c|}
\hline & Dextrose gel group & Non-dextrose gel group & $\boldsymbol{p}$ value \\
\hline Dextrose gel \% (n) & 59 & 0 & \\
& $\begin{array}{c}71 \%(42 / 59) \text { had 1 dextrose gel. } \\
27 \%(16 / 59) \text { had 2 dextrose gels. } \\
2 \%(1 / 59) \text { had 3 dextrose gels. }\end{array}$ & & \\
& $80 \%(47 / 59)$ & $76 \%(79 / 104)$ & 0.59 \\
\hline Only feed \% (n) & $3 \%(2 / 59)$ & $11 \%(11 / 104)$ & 0.10 \\
\hline Only dextrose infusion \% (n) & $17 \%(10 / 59)$ & $13 \%(14 / 104)$ & 0.55 \\
\hline Both Feed and dextrose infusion \% (n) & $20 \%(12 / 59)$ & $24 \%(25 / 104)$ & 0.59 \\
\hline Total intravenous interventions \% (n) & & & \\
\hline
\end{tabular}

Table 2: Neonatal hypoglycaemia treatment summary.

\begin{tabular}{|l|c|c|c|c|c|}
\hline BGL & \multicolumn{2}{|c|}{ Dextrose gel group } & \multicolumn{2}{c|}{ Non-dextrose gel group } & $p$ value \\
\hline & $\mathrm{n}(59)$ & Intravenous treatment & $\mathrm{n}(104)$ & Intravenous treatment & \\
\hline$<1.0 \mathrm{mmol} / \mathrm{L}$ & 6 & $100 \%(6 / 6)$ & 3 & $100 \%(3 / 3)$ & \\
\hline $1.0-1.5 \mathrm{mmol} / \mathrm{L}$ & 21 & $19 \%(4 / 21)$ & 31 & $45 \%(14 / 31)$ & 0.05 \\
\hline $1.5-2.6 \mathrm{mmol} / \mathrm{L}$ & 32 & $6 \%(2 / 32)$ & 70 & $11 \%(8 / 70)$ & 0.50 \\
\hline
\end{tabular}

Table 3: Intravenous dextrose infusion based on levels of low BGL.

In the Dextrose gel group, neonatal hypoglycaemia was treated with oral dextrose gel as first line treatment (Table 2) along with enteral feed in $80 \%$ (47/59), intravenous dextrose infusion in $3 \%$ $(2 / 59)$ and combination of feed and intravenous dextrose infusion in $17 \%(10 / 59)$.

Whilst in the Non-dextrose gel group, neonatal hypoglycaemia was treated with enteral feed in 76\% (79/104), intravenous dextrose infusion in $11 \%(11 / 104)$ and combination of feed and intravenous dextrose infusion in 13\% (14/104). Overall, 20\% (12/59) of the babies in the Dextrose gel group required intravenous dextrose infusion compared to $24 \%$ (25/104) in the Non-dextrose gel group.

Table 3 shows the analysis of the data based on BGL. For BGL $<$ $1.0 \mathrm{mmol} / \mathrm{L}$, hundred percent babies in both the groups received dextrose infusion. For BGL 1.0 - 1.5 mmol/L, 19\% (4/21) received dextrose infusion in the Dextrose gel group compared to $45 \%$ $(14 / 31)$ in the Non-dextrose gel group ( $p=0.05)$. For BGL $1.5-2.6$ $\mathrm{mmol} / \mathrm{L}, 6 \%(2 / 32)$ received dextrose infusion in the Dextrose gel group compared to $11 \%(8 / 70)$ in the Non-dextrose gel group.

Dextrose gel group had shorter duration of intravenous dextrose infusion compared to Non-dextrose gel group (2 days versus 3 days; $p=0.02$ ) and shorter length of stay in the Special Care Nursery ( 4 days versus 5 days; $p=0.38$ ). There was no difference when stratified separately for preterm and term babies.

\section{Discussion}

Blood glucose screening and neonatal hypoglycaemia management guidelines vary widely amongst different neonatal units [1821]. Studies have demonstrated oral dextrose gel together with enteral feeding improved the blood glucose concentration in babies with hypoglycaemia [15,22].

In our study, less babies in the Dextrose gel group required intravenous dextrose infusion compared to the Non-dextrose gel group (20\% versus 24\%; Table 2), especially for BGL 1.0 - 1.5 $\mathrm{mmol} / \mathrm{L}$ ( $19 \%$ versus $45 \%, \mathrm{p}=0.05$; Table 3 ). Also, the duration of dextrose infusion was lower in the Dextrose gel group compared to Non-dextrose gel group $(p=0.02)$. Our study is the first prospective study to our knowledge which has reiterated the use of oral dextrose gel as first line treatment for neonatal hypoglycaemia reducing the need for intravenous dextrose infusion. This has been reported in literature in a retrospective study [23].

The potential of less intravenous cannulation with use of dextrose gel would complement the continuing effort of avoiding painful invasive procedures in newborn babies, minimising mother-infant separation and mitigating the intravenous cannula associated complications such as phlebitis, local and systemic infections and extravasation injuries though intravenous cannulation is a common practice in neonatal units $[24,25]$. This is helpful especially where provision of prompt intravenous cannulation for dextrose infusion may not be available [24]. 
Our study also showed a combination therapy of feed and dextrose infusion was more prevalent in Dextrose gel group (17\% versus 13\%; Table 2). This is perceived to be better than alone dextrose infusion as babies are likely to establish to full feeding earlier; thereby reducing their dependency on intravenous cannulation for a prolonged period.

Previous studies have indicated use of single dose of dextrose gel $200 \mathrm{mg} / \mathrm{kg}$, though in our study, 71\% infants received one dose, $27 \%$ received two doses and only one infant received three doses of dextrose gel [16]. For babies with $\mathrm{BGL}<1.0 \mathrm{mmol} / \mathrm{L}$, one dose of oral dextrose gel was used as first line treatment whilst preparing for intravenous dextrose infusion to initiate hypoglycaemia treatment. However, this practice has not been reported in literature but in absence of any known side effect of oral dextrose gel, this practise may be pragmatic.

The average stay of babies in the Special Care Nursery was less for Dextrose gel group ( 4 days') compared to the Non-dextrose gel group (5 days'). Earlier studies also have highlighted a significant reduction in admission to neonatal unit for neonatal hypoglycaemia and improved breast feeding practises with oral Dextrose gel therapy [13]. At discharge from the Special Care Nursery, all babies were on breast feed with or without supplemented expressed breast milk or formula feeding. Studies have indicated dextrose gel does not interfere with subsequent feeding [26].

There were less number of babies in dextrose gel group because babies with existing intravenous access were treated with dextrose infusion as per the revised hypoglycaemia policy and did not qualify inclusion as they did not receive Dextrose gel. This was a major limitation of the study.

\section{Conclusion}

Oral dextrose gel may be effective treatment option for asymptomatic neonatal hypoglycaemia with BGL 1.0 - $1.5 \mathrm{mmol} / \mathrm{L}$ in $\geq$ 35 weeks' gestation age group. This is vital for neonatal units with limited access to immediate intravenous cannulation especially in a special care nursery set up. Oral dextrose gel also reduced the duration of intravenous dextrose infusion for asymptomatic neonatal hypoglycaemia.

\section{Acknowledgements}

We extend our acknowledgement to Ms Zhixin Liu, PhD Statistical Consultant, University of New South Wales Sydney NSW for her assistance with statistics.

\section{Funding Source}

No funding was secured for this study.

\section{Financial Disclosure}

No financial relationships relevant to this article to disclose.

\section{Conflict of Interest}

The authors have no conflicts of interest to disclose.

\section{Contributors' Statement}

Dr Bithi Roy conceptualized and designed the study, designed the data collection instruments, assisted in collecting data, carried out the analyses, drafted and reviewed the manuscript.

Justine Caparaz and Tracy Hynes collected data and revised the manuscript.

Dr Dharmesh Shah and Dr Tushar Bhuta reviewed the manuscript for important intellectual content.

All authors approved the final manuscript as submitted and agree to be accountable for all aspects of the work.

\section{Bibliography}

1. Rozance PJ. "Update on neonatal hypoglycaemia". Current Opinion in Endocrinology, Diabetes, and Obesity 21.1 (2014): 45-50.

2. Rasmussen AH., et al. "Retrospective evaluation of a national guideline to prevent neonatal hypoglycaemia". Pediatrics and Neonatology 58.5 (2017): 398-405.

3. VanHaltren $\mathrm{K}$ and Malhotra A. "Characteristics of infants at risk of hypoglycaemia secondary to being 'infant of a diabetic mother". Journal of Pediatric Endocrinology and Metabolism 26.9-10 (2013): 861-865.

4. Pettit KE., et al. "The association of antenatal corticosteroids with neonatal hypoglycemia and hyperbilirubinemia". Journal of Maternal-Fetal and Neonatal Medicine 27.7 (2014): 683686.

5. Yamamoto JM., et al. "Large-for-gestational-age (LGA) neonate predicts a 2.5 - fold increased odds of neonatal hypoglycaemia in women with type 1 diabetes". Diabetes/Metabolism Research and Reviews 33.1 (2017): 01.

6. De Leon DD and Stanley CA. "Congenital Hypoglycemia Disorders: New Aspects of Etiology, Diagnosis, Treatment and Outcomes: Highlights of the Proceedings of the Congenital Hypoglycemia Disorders Symposium, Philadelphia April 2016". Pediatric Diabetes 18.1 (2017): 3-9.

7. Tin W. "Defining neonatal hypoglycaemia: a continuing debate". Seminars in Fetal and Neonatal Medicine 19.1 (2014): 27-32. 
8. Arhan E., et al. "Neonatal hypoglycemia: A wide range of electroclinical manifestations and seizure outcomes". European Journal of Paediatric Neurology 21.5 (2017): 738-744.

9. Cakmakci H., et al. "Transient neonatal hypoglycemia: cranial US and MRI findings". European Radiology 11.12 (2001): 25852588.

10. Yalnizoglu D., et al. "Neurologic outcome in patients with MRI pattern of damage typical for neonatal hypoglycaemia". Brain and Development 29.5 (2007): 285-292.

11. Mahajan G., et al. "Neurodevelopmental Outcome of Asymptomatic Hypoglycemia Compared With Symptomatic Hypoglycemia and Euglycemia in High-Risk Neonates". Pediatric Neurology 74 (2017): 74-79.

12. Tam EW., et al. "Occipital lobe injury and cortical visual outcomes after neonatal hypoglycaemia". Pediatrics 122.3 (2008): 507-512.

13. Ter M., et al. "Implementation of dextrose gel in the management of neonatal hypoglycaemia”. Journal of Paediatrics and Child Health 53.4 (2017): 408-411.

14. Harris DL., et al. "Dextrose gel for neonatal hypoglycaemia (the Sugar Babies Study): a randomised, double-blind, placebocontrolled trial". Lancet 382.9910 (2013): 2077-2083.

15. Weston PJ., et al. "Oral dextrose gel for the treatment of hypoglycaemia in newborn infants". Cochrane Database of Systematic Reviews 5 (2016): CD011027.

16. Hegarty JE., et al. "Prophylactic Oral Dextrose Gel for Newborn Babies at Risk of Neonatal Hypoglycaemia: A Randomised Controlled Dose-Finding Trial (the Pre-hPOD Study)". PLOS Medicine 13.10 (2016): e1002155.

17. Stomnaroska-Damcevski O., et al. "Neonatal Hypoglycemia: A Continuing Debate in Definition and Management". Pril (Makedon Akad Nauk Umet Odd Med Nauki) 36.3 (2015): 91-97.

18. Adamkin DH. "Neonatal hypoglycaemia". Current Opinion in Pediatrics 28.2 (2016): 150-155.

19. Ramsden L., et al. "Paediatric hypoglycaemia; are we investigating appropriately and adequately?". Postgraduate Medical Journal 93.1103 (2017): 519-522.

20. Dalgic N., et al. "Transient neonatal hypoglycemia--long-term effects on neurodevelopmental outcome". Journal of Pediatric Endocrinology and Metabolism 15.3 (2002): 319-324.
21. Harris DL., et al. "A survey of the management of neonatal hypoglycaemia within the Australian and New Zealand Neonatal Network". Journal of Paediatrics and Child Health 50.10 (2014): E55-E62.

22. Harris DL., et al. "What Happens to Blood Glucose Concentrations After Oral Treatment for Neonatal Hypoglycemia?" The Journal of Pediatrics 190 (2017): 136-141.

23. Rawat M., et al. "Oral dextrose gel reduces the need for intravenous dextrose therapy". Biomedicine Hub 1.3 (2016): 448511.

24. Legemaat M., et al. "Peripheral intravenous cannulation: complication rates in the neonatal population: a multicenter observational study". Journal of Vascular Access 17.4 (2016): 360-365.

25. Scheans P., et al. "Using Dextrose (Glucose) Gel to Reverse Neonatal Hypoglycemia”. Neonatal Network 36.4 (2017): 233-238.

26. Weston PJ., et al. "Dextrose gel treatment does not impair subsequent feeding". Archives of Disease in Childhood - Fetal and Neonatal 102.6 (2017): F539-F541.

\section{Volume 2 Issue 10 October 2019 (C) All rights are reserved by Bithi Roy., et al.}

